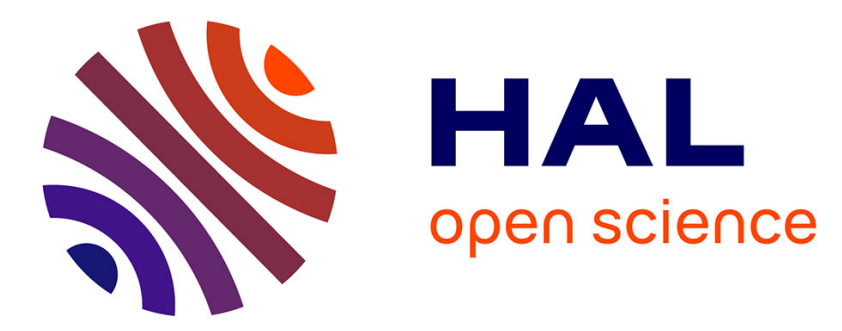

\title{
Developing a low carbon electricity economy: Smart grid and smart users Developing a Low Carbon Electricity Economy: Smart Grid and Smart Users
}

O S I Fayomi, Maya Julian, I G Akande, O E Atiba, O S Ohunakin

\section{- To cite this version:}

O S I Fayomi, Maya Julian, I G Akande, O E Atiba, O S Ohunakin. Developing a low carbon electricity economy: Smart grid and smart users Developing a Low Carbon Electricity Economy: Smart Grid and Smart Users. AIP Conference Proceedings, 2019, 2123, 10.1063/1.5116997 . hal-02938905

\section{HAL Id: hal-02938905 https://hal.science/hal-02938905}

Submitted on 15 Sep 2020

HAL is a multi-disciplinary open access archive for the deposit and dissemination of scientific research documents, whether they are published or not. The documents may come from teaching and research institutions in France or abroad, or from public or private research centers.
L'archive ouverte pluridisciplinaire $\mathbf{H A L}$, est destinée au dépôt et à la diffusion de documents scientifiques de niveau recherche, publiés ou non, émanant des établissements d'enseignement et de recherche français ou étrangers, des laboratoires publics ou privés. 


\section{Developing a low carbon electricity economy: Smart grid and smart users}

Cite as: AIP Conference Proceedings 2123, 020070 (2019); https://doi.org/10.1063/1.5116997

Published Online: 17 July 2019

O. S. I. Fayomi, Maya. Julian, I. G. Akande, O. E. Atiba, and O. S. Ohunakin

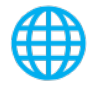

\section{Conference Proceedings}

Get $30 \%$ off all print proceedings!

\section{Enter Promotion Code PDF-30 at checkout}

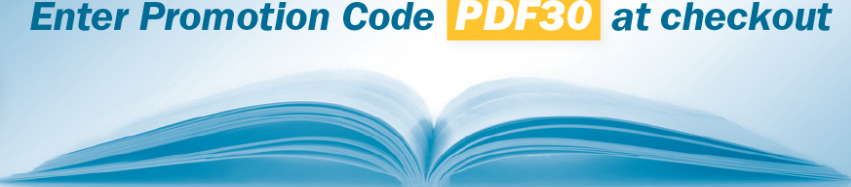




\title{
Developing a Low Carbon Electricity Economy: Smart Grid and Smart Users
}

\author{
O.S.I. Fayomi ${ }^{1,4, a)}$, Maya. Julian², I.G. Akande ${ }^{3}$, O.E Atiba ${ }^{1}$ O.S. Ohunakin ${ }^{1}$, \\ ${ }^{I}$ Department of Mechanical Engineering, Covenant University, Ota, Ogun State, Nigeria. \\ ${ }^{2}$ Universite de Lorraine, LGIPM, 3 Augustine Fresnel, BP 45112, 57073 METZ Cedex 03, France. \\ ${ }^{3}$ Department of Mechanical Engineering, University of Ibadan, Ibadan, Oyo State, Nigeria. \\ ${ }^{4}$ Department of Chemical, Metallurgical and Materials Engineering, Tshwane University of Technology, \\ Pretoria, South Africa. \\ ${ }^{a)}$ Corresponding emails:ojosundayfayomi3@gmail.com
}

\begin{abstract}
Low-carbon electricity economy has become the major area of research for many countries that have made great efforts towards ensuring its gradual development in their society. A great level of understanding of the various features and benefits that the smart grid system offers to both the power producing company and the smart users (i.e. consumers who are aware of the benefits that the system offers) is a major contribution to the interest of these countries in ensuring its development to full functionality at maximum efficiency. Various researches have indicated that complete development and satisfactory function of new smart grid systems can be accomplished, although there may be some technical constraints. Therefore, this research was carried out to create a level understanding of the low carbon electricity economy (smart grid system) review the development progress that have been attained by some major countries of the world.
\end{abstract}

Keywords: Low-carbon; Smart grid; Smart metering; Electricity.

\section{INTRODUCTION}

The continuous progress that has been taken place, for example the development of low carbon sources such as windmills and invented automotive machines like the electricity-driven cars tends to place a form of challenge against the electricity power plants of some nations. The best approach is to exchange the old wires used for electricity transmission with new and reliable ones that have been tested with various experiments and found to be duly functional. The old methods which involves the process of transmitting electricity from far locations with the use of power cables all the way to residential locations have caused a lot of problem, although other perspectives involved also contribute [1]. The final improvements and developments will be as a result of the various contributions during the process. The amazing rate that users are always ready to improve the place of residents and annual activities will determine the out turn of the smart grid system and also show the influence it will have on nations worldwide towards its accomplishment [2], [3]. According to Geels, (2008) the involvement of the Strategic Niche Management (SNM) has also contributed in the development and commercialization of the smart grid system towards ensuring its success. The use of information communication technologies (i.e. ICT) in combination with the power grids towards its advancement is the phenomenon in which the word 'smart grid' is derived. Many of the amazing merits that the smart grid system offers against all odds includes;

- They continuously improve the power delivery method of electricity grids by increasing its efficiency,

- This also assists it in reducing energy losses and so many more.

The introduction of smart grid systems is very crucial but has been qualified by varying objections from policymakers, investors and key stakeholders particularly, the producer and consumer. Based on the producer, the urge to immediately produce and supply electricity could lead to the generation of unstable and less useful power which greatly affects the progress of low carbon economy [4]. This hazardous incidence grows in accordance to the involvement of wind energy due to its fluctuation. Similarly, the consumers are bound to have high demand for electricity even when tariff-cost keeps on rising steadily. A newly developed urban environment must have within its environs some electricity infrastructures like gas or steam turbines, heater elements and various pumps whereby if all combined together, already renders the environment in constant need of electricity 
(Van Eck, 2010). The inclusion of more advanced electric devices like electricity-driven cars could double the demand for electricity.

There is a general hypothesis that with the gradual growth of the smart grid system, there will be a need to scale-up the volume of electricity as specified by environment. For example, if Nigeria aims at the use of smart grid system in the future, the current power stations must be improved and old and outdated electric equipment must be replaced duly. Some great nations still make use of transmission cables that were installed about 50 years ago without the thought of replacing it [5]. The area of investments into the electricity sector is also an effective catalyst towards the advancement of the low carbon electricity economy. The plans, decisions and budgets carried out by various nations of present will largely reflect on the future results that will be attained for the electricity sectors in the states [6].

Although researches have been made towards achieving a low carbon electricity economy, it is still quite certain of the cost, the life span and the proximity range that this systems can offer. Moreover, the introduction of the smart grid systems will be by far better and more advanced than our old stations (The Economist, 2004). The producers and marketers of this smart grid systems are quite certain that the consumers will even be willing to upgrade to this system due to the fact that most consumers have a strong insight of how profitable, reliable and efficient that this low carbon electricity economy can offer. The consumers could also assume that the right to their privacy could be at stake. Annually, many court processes have specifically been based on the aspect of personal privacy when installing electric components in a home [7].

Stephens, Wilson and Peterson (2015) identified some major barriers that affect the involvement of users in the improvement smart grids and smart metering. The first barrier is that this electricity generated cannot be sold by consumers to other interested users within the environment. The next barrier is the rate at which the prices could change from time to time without explaining to the customers why this is so rendering the consumers discouraged and regretting making use of the smart grid system. The last barrier is that the consumers have to duly pay for electricity supply while those large organisations that tap directly from the electricity source do not pay thereby giving a large partial difference between the organisations and the urban users. The unfair distribution of electricity between large organizations and urban users will always be a problem [8].There are certain problems associated with the acceptance of the new low-carbon technology for their environments [9]. Therefore, issue of political involvement in the electricity sector of a nation which involves the embezzlement of the profits made which could influence development in the low-carbon energy generation economy. Furthermore, the discouragement of community contributions and suggestions towards its improvement. The final reason is the failure of the market sector to explain to the understanding of the users the options that the low carbon economy has to offer to their satisfaction

\subsection{Smart Grid Systems and Users}

Electricity sector has massively evolved for a long period of time (30 years and above) from an engineering dependent sector to the combination of the market sector. This form of change is very challenging and takes a long while to be attained. The electric components used since the $18^{\text {th }}$ century managing to stand out from the current changes electricity systems. A major factor has to do with the maintenance of the power stations in a community. As smart grid systems continue to progress, a lot of definitions have been made based on it. A description of the smart grid is that it produces and transmits electrical currents more efficiently and reliably. It makes use of creative tools and resources for the production, transmission and consumption by the users. It enables the users to have various options for electricity distribution for satisfactory consumption [6].Furthermore, it has been agreed that the fundamental improvement of the smart grid system includes electricity production, experimentations and reliable and efficient appliances [10]. One major application of this innovation is in the use of electricity preservation i.e. preserving them in storage equipment. This application also has some constraints as it largely leads to power losses in the station and causes reduction in profit [4], [7].Smart grids can be seen as electricity networks that are able to gather information on all the users that are connected to it based on their behaviour and actions for provision of viable energy supply [10]. Basically, smart-grids may have instruments known as smart meters that quantify energy outputs instantaneously and they may also be equipped with sensors that measure certain data and these are all put in place in order to give generators and consumers their energy needs in terms of demand, reduce the length of outages and also get data on failure in order to re-organize the grid after failures [6].

In most nations, generation of electricity is done in huge power stations, then transported through transmission lines to the consumers. This method has been the norm for years and even though it is effective it introduces some energy inefficiencies such as resistive loss in the transmission lines. Using a smart-grid system could enable officials regulate with more precision the electric flows on the grid via Flexible AC Transmission Systems and sensors known as phasor measurement units. Smart users are the end users of the smart grid technology, they are the consumers. For the adaptation and shift towards low-carbon electricity, users have to be accepting of it, hence they play a major role. Most times, people feel that smart grid development should be based 
on technological advances alone but the important participation of the end users should also be recognized. (Daphne Geelen et al, 2013).

\subsubsection{Strategic niche management (SNM)}

The SNM aims at performing analysis and adding improvements to the transmission of electricity using low carbon electricity economy. Its objectives are to explore the intrinsic part of the community development. SNM outlined three major processes for its successful development. According to Keemp et al., (1998) the three processes include (i) developing a report on the intentions and plans, (ii) establishing social expertise, (iii) Increasing awareness based on the understanding of the procedures [11]. The SNM also focuses on contributing to the development of reliable methods of generation and transmission of low carbon electricity to the community. Several researches have shown that SNM largely contributes to the development of the smart grid system [11]-[13].

\subsubsection{Demand side management (DSM)}

For the smart grid to function properly, DSM have to be introduced. DSM is a tool whose primary function is to allow the demand of a product follow the supply of that same product. It is used to transfer loads from a period when it is in high demand to a period when the need is highly reduced. The use of DSM in residential areas is a new development. For DSM to work properly the equipment would have to be smart, that means that the users should be able to control these equipment comfortably from wherever they are. The smart-meter also has to be incorporated into DSM so that information can be sent from the consumer to the system and vice-versa [12], [13].

\subsubsection{Case study of smart grid system in the UK}

One major nation which have participated on growth of this technology is United Kingdom. They have experimented in using of high-speed air and solar electricity generation. This has largely contributed to the improvement of their community has it can supply sufficient power to their (EVs) thereby demanding a lot of electricity. This has also provided many efficient power generating companies for UK. The Smart Grid European Technology Platform defines electricity as the means by which a connected pair of electrical units have the ability to generate and deliver electricity to the consumers also known as users [14]. The smart-grid system offers much benefits, hence its development. The generation of renewable energy is one of the functions that the low carbon economy offers to the community. A key benefit that it also offers is the provision of a network that is stable in other words, those cause default in its transmission process. The next benefit is the assistance it offers in ensuring that emissions from the power plant during power generation processes is reduced to a minimum [14], [15].The study carried out by [14] shows that although this system provides a lot of benefits, it also has some limitations. The various barriers are listed below:

- Communication issue is a contributing issue for low-carbon economy. The process in which the devices communicate with each other and including their networking capability.

- Protection of data is not always put into serious consideration leading to a very low level of cyber security and vital information of the consumer to be accessed by any individual.

- Marketability of the smart grid system is a major barrier to the growth of smart-grid. The consumers are not well informed of the full package that the smart grid offers and its major improvement in the power generating sector of their community.

The UK's erratic financial recuperation implies natural goals reduction in social plan also a need is a reclamation of development. Progress with weight upon DECC in organisations, also an administration which can lessen money related help in better strategies [14], [16]. A specified agency cuts through various petroleum sectors and presents strategies for contention with DECC's extended haul gas decrease destinations. Toward the conclusion of a period, various mineral control plants close because of great thermal reaction scenarios, many atomic plants achieved a completion regarding various duties, with offer of carbon from UK age blend increments consistently, supported by the limit component [15], [16]. Despite the fact that breeze age keeps on developing, minimum readiness in receiving more yearning strategy forms in regions is inevitable. Great costs set up from agreements of low-carbon age go about in form of value to ensure an atomic business, including administration able to alter the process. Amidst a period of development starts on different stations. This shows that there is still a level of doubt on the development of low-carbon economy a long time from now. This is included for both private and non-private organisations which all aim to reduce the level of doubt for the development of lowcarbon economy. The misconceptions can be said to be caused by high social personalities like governors and senators of a nation. Furthermore, for the continual progress of smart-grid systems, the governors, senators, etc. should not misuse the power that has been handed unto them.[14]-[16] 


\subsubsection{Case study of smart grid system in Brazil}

Brazil has a generally long history in advancing vitality effectiveness at definite client level. A milestone of this procedure is the Brazilian Labelling Program, propelled in 1984, as immediate result of high costs of vitality around then. This program was facilitated for purpose of National Organization of Metrology, which sets norms for assessment, positions the execution of vitality gear and forces a classificatory marking to educate buyers, with a name like different nations. It is notable the solid connection between monetary improvement and vitality utilization. Be that as it may, vitality proficiency can uncouple and relativize this relationship, keeping the level of generation and welfare and lessening the vitality utilization by diminishing vitality misfortunes, not influencing the helpful utilization of vitality. With this respect, Figures 5 and 6 present the development of the Brazilian for the period 1970 up to 2012, with estimations of aggregate essential vitality supply (TEPS) and add up to power utilization per capita and per GDP, are additionally called vitality and power powers. For this period, it tends to be watched an important increment in the per capita request of vitality (over $100 \%$, including all sources) and power (over 600\%), in accordance with the universalization and pay per capita development forms. Anyway wonderful, after diminish in the start of the period, the vitality force remained around stable, while the power force expanded, demonstrating the likelihood of advancing all the more conclusively the proficiency in vitality and power utilize.

\subsubsection{Case study of the Solstice Company (West-Africa)}

The solstice company is an organisation established mainly for the purpose of innovation and development in technological ideas brought forward in request of their assistance. This company has greatly assisted a lot of other organisations both private and corporate who aim to fully improve the use of smart grid systems in their country. Presently, this company is working in partnership with an organisation in improving the ease of accessibility of the smart meter in various homes in order to reduce societal constraints such as security purposes.

\subsection{Smart Grid Functionalities}

In a review done by [6] on smart grid technologies, they explained some of the main characteristics and functionalities of the smart grid. Some of which are: efficiency, reliability and security of the electric grid: The smart grid is very reliable. It promotes fault detection and self-healing. Also, efficiency is also improved through the remote controlling of hybrid generation for unstable distribution. Integration of Smart Appliances and consumer devices: Smart appliances are basically appliances that have the ability to work hand in hand with the smart grid. That is, they are able to communicate with the smart grid. They work in such a way that they turn off during peak hours controlling electricity use based on the power requirements of the household .Deployment of Smart meters: This ensures various transmissions between meters and consumers. They give more accurate description of the bills and the end users are more in control of the amount of energy consumed using these smart meters. They involve sensors, power quality management and power outage notification. Some primary functions of the smart grid are real time monitoring and reaction, rapid isolation and anticipation .

\subsection{Microgrids}

Smart microgrids are going to be very helpful in achieving the prospects of smart grids. Micro grids represent small control systems in form of several megawatts that consists of disseminated generators, independent weight centres also capability of operation in conjunction through larger grids as well as operate independently on its own. Microgrids are very important as they help to improve reliability due to the fact that they can help provide power to the larger grid and in the case of an outage they can produce power independently on their own and as such they are a good support system as well as back-up system [13].

\subsection{Smart Users}

Smart users are the end users/consumers in a smart grid system. Normally users are not really involved with the goings on of the power companies but with the smart grid system functionality would be reduced if users are not in the picture. Typically, DSM is used to changed weights from top stages to stages when the demand has reduced. For appliances in the home to be able to apply DSM they have to be smart appliances, that is, they have to be able to be operated from a distance even when the home owner is at school or work [17].Now there are more active roles for the consumers for electricity generation. Customers of different sizes, like industrial or even residential can now participate in the balancing of electricity system. This can be achieved using the smart meters, also DSM which involves capability of controlling electricity convention in such a way that demand could follow 
supply and not the other way around as it is being done now. This will enable users to sufficiently manage their energy consumption and also conserve energy in the process [6].

In a study done by [8], [17] on an overview of smart grid customer's engagement and acceptance, they mentioned that very little attention is paid to the end users or consumers and this should not be so because they play a very vital role in smart grid development. Most times it is assumed that the customers would just accept the smart grid technology but as it is commonly said assumption is the lowest form of knowledge, without proper research on what will make users accept the smart grid technology.

Consumers are one of the major and important smart grid domains. There are three main interrelated pillars that affect the consumer end as mentioned by [8], [17]. These pillars are the smart customer, smart utility and smart market. The smart customer refers to the technologies that will help the consumer in the monitoring and controlling of the energy consumption. The smart utility provides the users with appropriate monitoring and control of pricing and other energy management schemes. The smart market basically integrates the other two pillars, that is, the technology and the utility to create an economically friendly solution for the future.

For smart grid to really take off, there has to be acceptance by the consumers and there are three dimensions of acceptance and these are market approval, public approval and socio-political acceptance. Market approval entails distributors, producers etc. investing in smart grid technologies. Community acceptance include local stakeholders and local authorities embracing smart grid technology. Socio-political acceptance involves the policy makers that create and foster policies that aid market and community acceptance [6].

\section{BENEFITS AND CHALLENGES FACING CONSUMERS ENGAGEMENT}

\subsection{Benefits of Smart Grid System}

Research done by [6], [18] states major benefits of the smart grid include an economic and more environmentally-friendly community. The benefits were also examined by (Lorena \& Lochinvar, 2016)(Smart Grid, 2013) from a consumer perspective and they are[6]:

- Reliability: By using the smart grid system, the price for power disruption are minimized and also the possibility of light-outs is reduced to a great extent.

- Economic: The development of the smart grid system will give rise to job creation, it could also help the country in the sense that it will raise the gross domestic product as well as reduce the economic[20].[20] Gave the benefits in a different view-point also the following benefits were stated:

- It facilitates simultaneous observation and regulation.

- The measurement with sensing tools help to assist improved feedback to various system situations.

- The use of advanced control algorithms/smart electronics helps to improve system control and optimization.

\subsection{Challenges Facing Consumers Engagement}

A few challenges facing smart grid development were given and the two primary challenges are given below:

- Privacy

- RF (Radio Frequency) smart meters

Privacy: This is a major challenge facing smart grid development. Smart meters are designed in such a way that they are able to capture detailed information about user's electricity usage mostly at 15 minutes intervals over several months. The problem with this is that this information can give a very detailed description about a person's everyday life, his/ her personal habits etc. It is not clearly stated if the material is owned by consumers and as such the information can be very valuable to places like marketing firms and also criminals and this poses a major threat [18], [19]. RF (Radio Frequency) smart meters: This is another concern that has been raised by consumer groups using the technology. The precautions of RF signal in communication to smart meter is a challenge. Users argue that RF signals are conducted all through, daily in households but experts have countered this by saying that electronics broadcast RF signals in the home throughout the day and the smart meter does this for just 15 minutes every day [18], [19].

\section{CONCLUSION}

The smart grid system is a way towards achieving a low-carbon electricity economy. Electricity transmission to our households is better and more efficient with the smart grids and it also contributes in reducing green-house effect. It is a very reliable and efficient such that there is communication between the users and grids and this helps to conserve energy and get the particular energy requirements of the consumers. Although some challenges 
exist in expansion of smart-grid, further investigation would get viable solutions and in a matter of years the transition to smart grid will be an achievable feat.

\section{ACKNOWLEDGEMENTS}

The author acknowledges Covenant University for the financial support offered for the publication of this research.

\section{REFERENCES}

1. J. Percebois, "Smart Meters and SmartGrids: an Economic Approach," in Smart Grids, 2013, pp. 301-319.

2. H. Mignon, "Transmission Grids: Stakeholders in SmartGrids," in Smart Grids, 2013, pp. 57-78.

3. R. Masiello and KEMA, Inc, Smart Grid Roadmap for Renewables Integration: Final Project Report. 2013.

4. J. Guerrero et al., "Distributed Generation: Toward a New Energy Paradigm," IEEE Ind. Electron. Mag., vol. 4, no. 1, pp. 52-64, 2010.

5. A. Perry, "The ENSG Route Map and how smart grids fit into the future energy context," in IET Conference on Smart Grid 2010: Making it a reality, 2010.

6. M. Kurth, "Smart Metering, Smart Grids, Smart Market Design," in Broadband Networks, Smart Grids and Climate Change, 2012, pp. 11-15.

7. M. Baddeley, "Behavioral Aspects of Smart Meters," in Smart Grid Handbook, 2016, pp. 1-11.

8. J. C. Stephens, E. J. Wilson, and T. R. Peterson, Smart Grid (R)Evolution. Cambridge University Press, 2015.

9. N. S. Wade, D. M. Greenwood, P. Papadopoulos, C. Keramisanos, and A. Laguna, "Forecasting and optimisation for multi-purpose application of energy storage systems to deliver grid services: case study of the smarter network storage project," in Energy Storage at Different Voltage Levels: Technology, integration, and market aspects, pp. 261-300.

10. A. Kiessling, M. U. Niemann, and F. Schmitt, "Why Smart Grids? / Warum Smart Grids?," ENERGYO. 2018.

11. R. Kemp, J. Schot, and R. Hoogma, "Regime shifts to sustainability through processes of niche formation: The approach of strategic niche management," Technology Analysis \& Strategic Management, vol. 10, no. 2, pp. 175-198, 1998.

12. G. Verbong, F. W. Geels, and R. Raven, "Multi-niche analysis of dynamics and policies in Dutch renewable energy innovation journeys (1970-2006): hype-cycles, closed networks and technology-focused learning," Technology Analysis \& Strategic Management, vol. 20, no. 5, pp. 555-573, 2008.

13. G. P. J. Verbong and F. W. Geels, "Exploring sustainability transitions in the electricity sector with sociotechnical pathways," Technol. Forecast. Soc. Change, vol. 77, no. 8, pp. 1214-1221, 2010.

14. D. Xenias, C. J. Axon, L. Whitmarsh, P. M. Connor, N. Balta-Ozkan, and A. Spence, "UK smart grid development: An expert assessment of the benefits, pitfalls and functions," Renewable Energy, vol. 81, pp. 89-102, 2015.

15. P. M. Connor, P. E. Baker, D. Xenias, N. Balta-Ozkan, C. J. Axon, and L. Cipcigan, "Policy and regulation for smart grids in the United Kingdom,” Renewable Sustainable Energy Rev., vol. 40, pp. 269-286, 2014.

16. P. M. Connor, C. J. Axon, D. Xenias, and N. Balta-Ozkan, "Sources of risk and uncertainty in UK smart grid deployment: An expert stakeholder analysis," Energy, vol. 161, pp. 1-9, 2018.

17. G. P. J. Verbong and F. W. Geels, "Pathways for sustainability transitions in the electricity sector: Multilevel analysis and empirical illustration," in 2008 First International Conference on Infrastructure Systems and Services: Building Networks for a Brighter Future (INFRA), 2008.

18. M. Fadaeenejad, A. M. Saberian, M. Fadaee, M. A. M. Radzi, H. Hizam, and M. Z. A. AbKadir, "The present and future of smart power grid in developing countries," Renewable Sustainable Energy Rev., vol. 29, pp. 828-834, 2014.

19. M. Fadaeenejad, M. A. M. Radzi, M. Z. A. AbKadir, and H. Hizam, "Assessment of hybrid renewable power sources for rural electrification in Malaysia,” Renewable Sustainable Energy Rev., vol. 30, pp. 299 $305,2014$.

20. M. Trabelsi, M. Ghanes, O. Ellabban, H. Abu-Rub, and L. Ben-Brahim, "An interconnected observer for modular multilevel converter," in 2016 IEEE Energy Conversion Congress and Exposition (ECCE), 2016.

21. O. B. Fakehinde, O. S. Fayomi, U. K Efemwenkieki, K. O. Babaremu, D. O Kolawole, \& S. O. Oyedepo, (2019). Viability of Hydroelectricity in Nigeria and the Future Prospect. Energy Procedia, 157, 871-878.

22. S. T. A., Okolie, O Ozuor,. O. Fakehinde, S. O. Ongbali, O. S. I, Fayomi, \& Agu, F. A. (2019). Study of Nigeria Geothermal Energy resources' Viability, Brief Production Techniques and Transportation. Energy Procedia, 157, 1475-1485. 